Investigation of Thermal High Cycle and Low Cycle Fatigue Mechanisms of Thick Thermal Barrier Coatings

Dongming Zhu and Robert A. Miller

Lewis Research Center, Cleveland, Ohio

Prepared for the

Thermal Barrier Coatings Workshop

sponsored by the TCB Interagency Coordinating Committee

Fort Mitchell, Kentucky, May 19-21, 1997

National Aeronautics and Space Administration

Lewis Research Center 
Available from

NASA Center for Aerospace Information 800 Elkridge Landing Road

Linthicum Heights, MD 21090-2934

Price Code: A03
National Technical Information Service 5287 Port Royal Road Springfield, VA 22100 Price Code: A03 


\title{
INVESTIGATION OF THERMAL HIGH CYCLE AND LOW CYCLE FATIGUE MECHANISMS OF THICK THERMAL BARRIER COATINGS
}

\author{
Dongming Zhu ${ }^{\dagger}$ and Robert A. Miller \\ Materials Division \\ National Aeronautics and Space Administration \\ Lewis Research Center, Cleveland, $\mathrm{OH} 44135$
}

\begin{abstract}
Thick thermal barrier coating systems in a diesel engine experience severe thermal low cycle fatigue (LCF) and high cycle fatigue (HCF) during engine operation. In this paper, the mechanisms of fatigue crack initiation and propagation in a $\mathrm{ZrO}_{2}-8 w t . \% \mathrm{Y}_{2} \mathrm{O}_{3}$ thermal barrier coating, under simulated engine thermal LCF and HCF conditions, are investigated using a high power $\mathrm{CO}_{2}$ laser. Experiments showed that the combined LCF/HCF tests induced more severe coating surface cracking, microspallation and accelerated crack growth, as compared to the pure LCF test. Lateral crack branching and the ceramic/bond coat interface delaminations were also facilitated by HCF thermal loads, even in the absence of severe interfacial oxidation. Fatigue damages at crack wake surfaces, due to such phenomena as asperity/debris contact induced cracking and splat pull-out bending during cycling, were observed especially for the combined LCF/HCF tests. It is found that the failure associated with LCF is closely related to coating sintering and creep at high temperatures, which induce tensile stresses in the coating after cooling. The failure associated with HCF process, however, is mainly associated with a surface wedging mechanism. The interaction between the LCF, HCF and ceramic coating creep, and the relative importance of LCF and HCF in crack propagation are also discussed based on the experimental evidence.
\end{abstract}

\section{INTRODUCTION}

Ceramic thermal barrier coatings have received increasing attention for advanced gas turbine and diesel engine applications. The advantages of using ceramic coatings include a potential increase in efficiency and power density and a decrease in maintenance cost. Zirconiabased ceramics are the most important coating materials for such applications because of their low thermal conductivity, relatively high thermal expansivity and excellent mechanical properties.

\footnotetext{
${ }^{\dagger}$ National Research Council-NASA Research Associate at Lewis Research Center.

Keywords: Thermal High Cycle and Low Cycle Fatigue, Ceramic Sintering and Creep, Fatigue Mechanisms
} 
However, durability of thick thermal barrier coatings under severe temperature cycling conditions remains a major question. It is known that two types of thermal fatigue transients exist in a diesel

engine $^{[1-3]}$. The first type of transient, which is associated with the start/stop and no-load/fullload engine cycle, generates thermal low cycle fatigue (LCF) in the coating system. The second transient type, which is associated with the in-cylinder combustion process, generates a thermal high cycle fatigue (HCF) with typical frequency on the order of $10 \mathrm{~Hz}$ (i.e., 1000-2600 RPM). The HCF transient can induce a temperature fluctuation of more than $200^{\circ} \mathrm{C}$ that will superimpose onto the steady-state engine temperature at the coating surface ${ }^{[2,3]}$. Therefore, the failure mechanisms of the thick thermal barrier coatings are expected to be different from the thin coatings under these temperature transients. The coating failure is related not only to coating thermal expansion mismatch and oxidation of the bond coats and substrates ${ }^{[4-6]}$, but also to the steep thermal stress gradients induced in the coating systems $[2,4,6-10]$. Although it has been reported $[7,11]$ that stresses generated by thermal transients can initiate surface and interface cracks in a coating system, the detailed mechanisms of the crack propagation and of coating failure under the complex LCF and HCF conditions are still not understood. In this paper, the thermal fatigue behavior of an yttria partially stabilized zirconia coating system under simulated thermal LCF and HCF engine conditions is investigated. The interaction between LCF and HCF cycles, and the impact of relative amplitudes of the LCF and HCF transients on the coating fatigue crack initiation and propagation are also discussed based on the experimental results and observations.

\section{EXPERIMENTAL MATERIALS AND METHODS}

A two layer thermal barrier coating system, consisting of a $\mathrm{ZrO}_{2}-8 w t . \% \mathrm{Y}_{2} \mathrm{O}_{3}$ ceramic coating and an intermediate $\mathrm{Fe}-25 \mathrm{Cr}-5 \mathrm{Al}-0.5 \mathrm{Y}$ bond coat, was plasma-sprayed onto steel angle iron $(203 \times$ side width $25 \times$ wall thickness $4 \mathrm{~mm})$ and rectangular bar $(127 \times 32 \times 12.7 \mathrm{~mm})$ substrates. The angle iron and rectangular substrate configurations were especially chosen to study the effect of specimen geometries such as corners, edges and flat surfaces on cracking patterns of the thermal barrier coating after thermal fatigue testing. The plasma spray conditions have been reported elsewhere ${ }^{[12]}$, as summarized in Table 1 . The thicknesses of the ceramic coating and the bond coat were about $1.6 \mathrm{~mm}$ and $0.28 \mathrm{~mm}$, respectively. Thermal LCF and $\mathrm{HCF}$ tests were conducted using a $1.5 \mathrm{KW}$ high power $\mathrm{CO}_{2}$ laser, as described previously [10, 13] . The $\mathrm{CO}_{2}$ laser is especially suited for testing $\mathrm{ZrO}_{2}$-based thermal barrier coatings because it can deliver a well-characterized and well-controlled heat energy to the surface of the ceramic coating. Since zirconia is opaque at the $10.6 \mu \mathrm{m}$ wavelength of laser beam [14], the light energy is absorbed by the coating surface rather than penetrating into the coating. In order to produce a 
lower power density suitable for simulating diesel engine conditions, and also to cover a larger test specimen area, a Plano Concave ZeSe lens with focal length $-330 \mathrm{~mm}$ was used to expand the laser beam to $32 \mathrm{~mm}$ in diameter. The laser test rig was controlled by a PC programmed to generate various LCF heating and cooling cycles. Backside air cooling was used to maintain desired temperature gradients across the coating system. Coating surface and backside metal temperatures were measured by a special $8 \mu \mathrm{m}$ infrared pyrometer and a type- $\mathrm{R}$ thermocouple, respectively. In laser LCF and HCF tests, the ceramic surface temperatures were set at $850^{\circ} \mathrm{C}$ and $950^{\circ} \mathrm{C}$, respectively, and the backside metal temperature were at $250^{\circ} \mathrm{C}$. The pure $\mathrm{LCF}$ cycles were generated by the continuous wave (CW) laser mode, and the HCF combustion cycles were simulated using the pulsed laser mode, as shown in Fig. 1. The LCF cycles, in either the pure LCF test or the combined LCF and HCF tests, were 5 minute or 30 minute heating cycles with a total heating time of 256 hours. Because the high energy laser pulse was used, an HCF component was inherently superimposed on the LCF cycles in the combined LCF and HCF tests. The laser pulse period and pulse width were fixed at 92 and 6 milliseconds (ms) respectively. The crack lengths were measured after the tests. The effect of pure HCF component on crack propagation was also investigated by a laser thermal shock test that has been described previously $[10,13]$. In this pure HCF test, the laser power was set at either 1600 or $900 \mathrm{~W}$, and the laser pulse heating time was set at $100 \mathrm{~ms}$. The pure HCF conditions generated maximum surface temperature swings of about $750^{\circ} \mathrm{C}$ and $420^{\circ} \mathrm{C}$. The sufficient cooling time allowed the specimen substrate temperature to remain cool throughout the testing. The crack lengths in the ceramic coating were also measured periodically up to 5000 cycles. The LCF and HCF tested coating surfaces and cross-sections were examined under both optical and scanning electron microscopes to obtain information on crack density and depth.

Table 1 Plasma spray parameters for $\mathrm{ZrO}_{2}-8 \mathrm{wt} \% \mathrm{Y}_{2} \mathrm{O}_{3}$ top coat and $\mathrm{FeCrAlY}$ bond coat

\begin{tabular}{|c|c|c|c|c|c|c|c|c|}
\hline $\begin{array}{l}\text { Coatings } \\
\text { materials }\end{array}$ & $\begin{array}{c}\text { Torch } \\
\text { power } \\
\text { KW }\end{array}$ & $\begin{array}{l}\text { Plasma } \\
\text { gas flow } \\
\text { rate } \\
\text { Standard } \\
\text { liter } / \mathrm{min} .\end{array}$ & $\begin{array}{l}\text { Carrier } \\
\text { gas flow } \\
\text { Standard } \\
\text { liter/min. }\end{array}$ & $\begin{array}{c}\text { Spray } \\
\text { distance } \\
\mathrm{mm}\end{array}$ & $\begin{array}{l}\text { Feed } \\
\text { rate } \\
\mathrm{g} / \mathrm{min} .\end{array}$ & $\begin{array}{c}\text { Torch } \\
\text { translatio } \\
\text { n rate } \\
\mathrm{mm} / \mathrm{s}\end{array}$ & $\begin{array}{c}\text { Air } \\
\text { cooling } \\
\text { condition } \\
\text { Psi }\end{array}$ & $\begin{array}{c}\text { Substrate } \\
\text { temperature } \\
{ }^{\circ} \mathrm{C}\end{array}$ \\
\hline $\begin{array}{c}\text { FeCrAlY } \\
\text { PRAX-AIR } \\
\text { FE213 } \\
44-74 \mu \mathrm{m}\end{array}$ & $\begin{array}{c}35 \\
(9 \mathrm{mB} \\
\text { plasma } \\
\text { torch, GH } \\
\text { nozzle }) \\
\end{array}$ & $\begin{array}{c}\text { Ar: } 56.6 \\
\mathrm{~N}_{2}: 9.4\end{array}$ & Ar: 8.3 & 127 & 68 & 1300 & 50 & 250 \\
\hline $\begin{array}{c}\mathrm{ZrO}_{2}-8 \% \mathrm{Y}_{2} \mathrm{O}_{3} \\
\mathrm{ZIRCOA} \\
9507 / 46 \\
44-74 \mu \mathrm{m}\end{array}$ & $\begin{array}{c}40 \\
(9 \mathrm{mB} \\
\text { plasma } \\
\text { torch, GH } \\
\text { nozzle })\end{array}$ & $\begin{array}{l}\mathrm{Ar}: 14.2 \\
\mathrm{~N}_{2}: 7.1\end{array}$ & Ar: 3.2 & 101.6 & 20 & 1000 & 50 & 250 \\
\hline
\end{tabular}




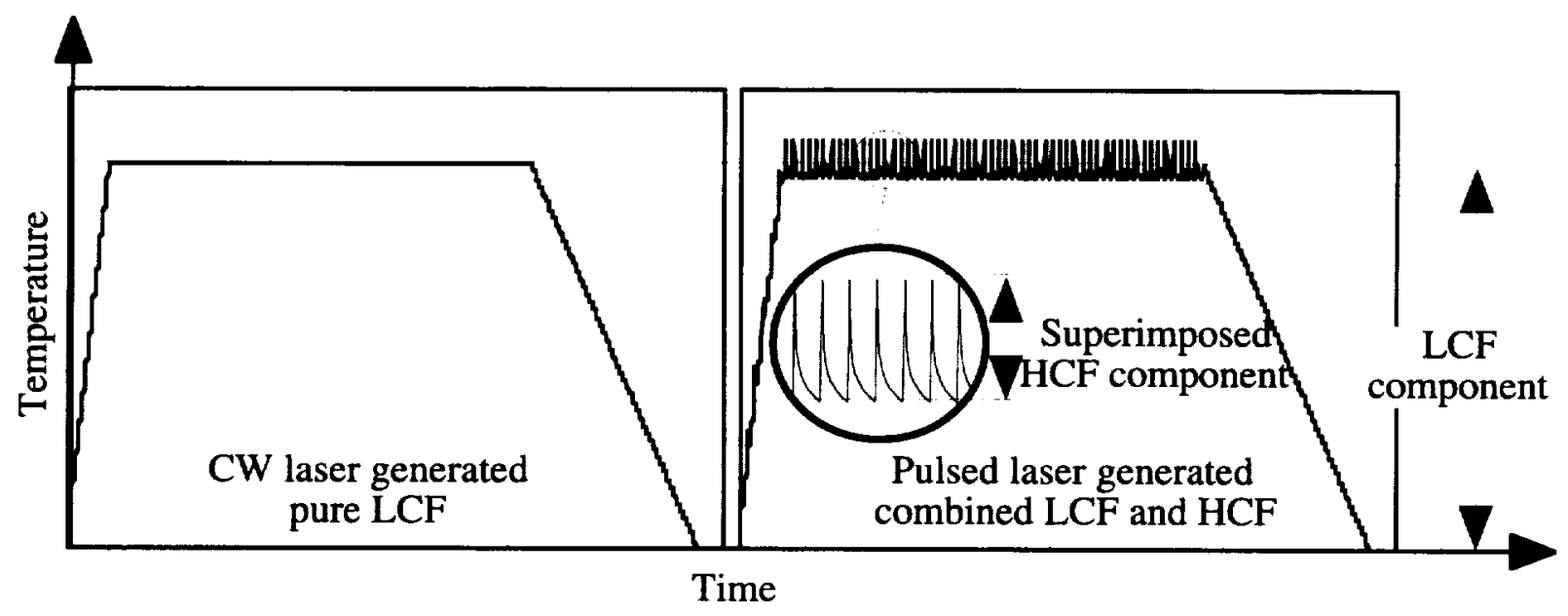

(a)

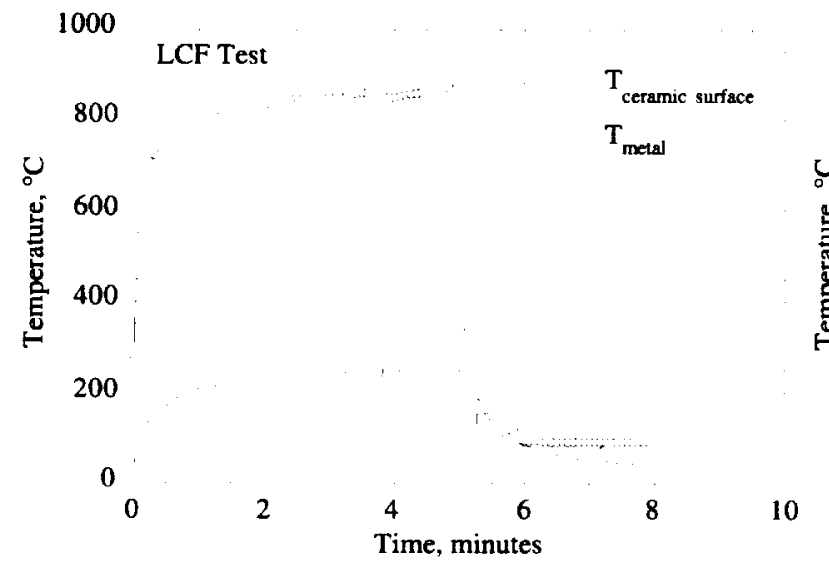

(b)

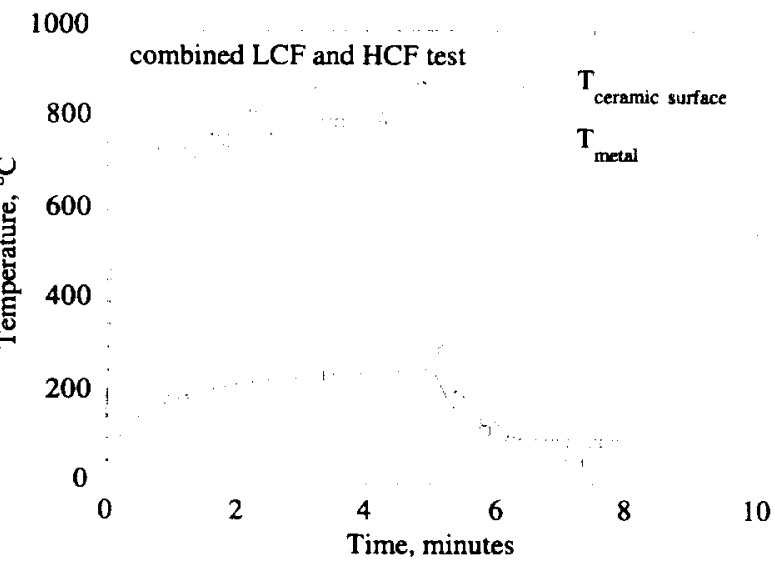

(c)

Fig. 1 High power laser simulated the pure LCF and combined LCF/HCF cycles in thermal barrier coating systems. (a) Schematic diagram showing LCF and superimposed LCF and HCF cycles; (b) and (c) Experimental measured temperature-time profiles during 5 minute heating/3 minute cooling LCF, and combined LCF/HCF tests, respectively. Note that in the HCF superimposed case in (c), the pyrometer response time is not fast enough to show the actual temperature response at the ceramic surface. 
When pulsed laser heating is used, a severe thermal transient will be induced even in the absence of LCF cycling. This temperature fluctuation under the HCF conditions was modeled using a finite difference approach ${ }^{[12,13]}$. The modeled results indicate that the HCF transient occurs only at the surface of the ceramic coating. This layer may be defined as the HCF interaction depth at which appreciable temperature fluctuation (greater than about $10 \%$ the surface temperature swing) will occur. The temperature swing, generated by the pulsed laser, increases with increasing laser power density and pulse width. The HCF interaction layer depth, which is independent of laser power density, increases with laser pulse width. Under the HCF condition of $6 \mathrm{~ms}$ heating, the interaction depth is about $0.15 \mathrm{~mm}$. The temperature profiles generated by the pulsed laser under a peak heat flux of $4.95 \mathrm{MW} / \mathrm{m}^{2}$ are illustrated in Fig. 2. This temperature fluctuation induces high-frequency cyclic stresses on the coating surface, with the predicted HCF stress amplitude of about $100 \mathrm{MPa}$ at $4.95 \mathrm{MW} / \mathrm{m}^{2}{ }^{[12]}$, as shown in Fig. 3. The dashed line in Fig. 3 represents the ceramic surface stress at the average steady state surface temperatures under the corresponding average heat flux $0.323 \mathrm{MW} / \mathrm{m}^{2}$.

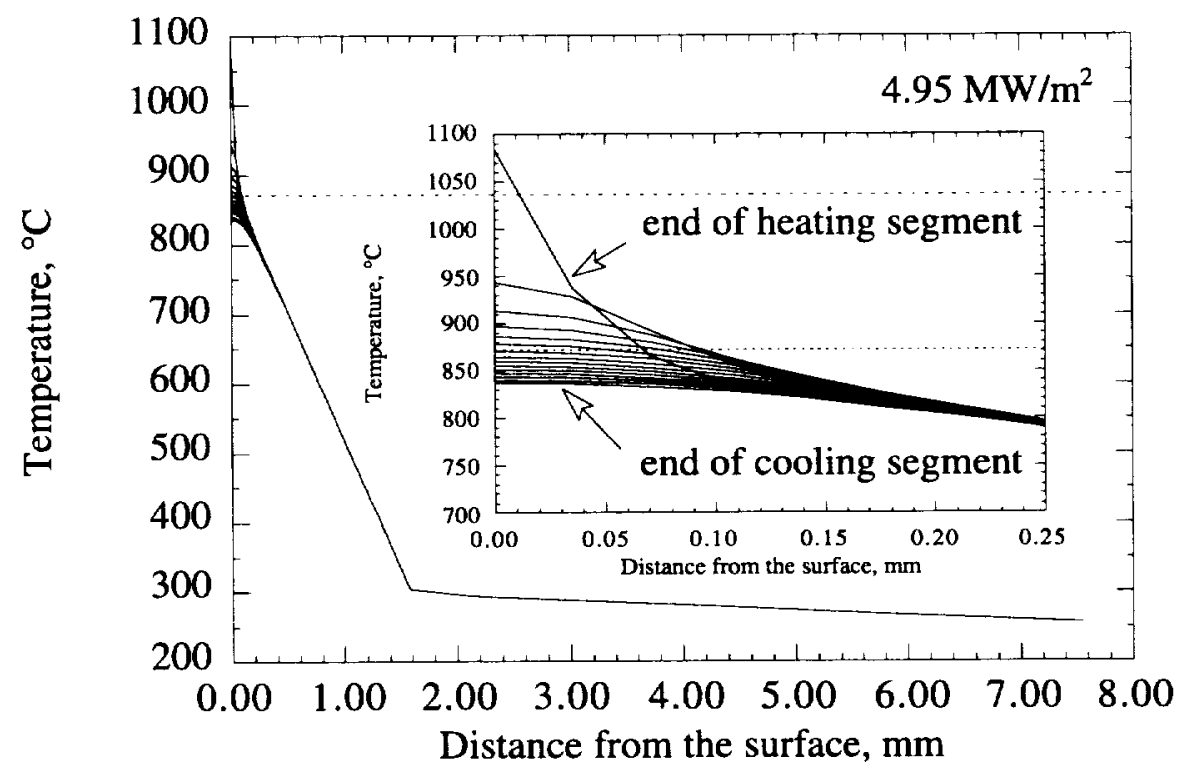

Fig. 2 Predicted temperature profiles generated by pulsed laser heating (pulse width $6 \mathrm{~ms}$ ). Under the HCF condition of $6 \mathrm{~ms}$ heating, the interaction depth with a considerable temperature swing is about $0.15 \mathrm{~mm}$ (dashed line represents the time-averaged surface temperature). 


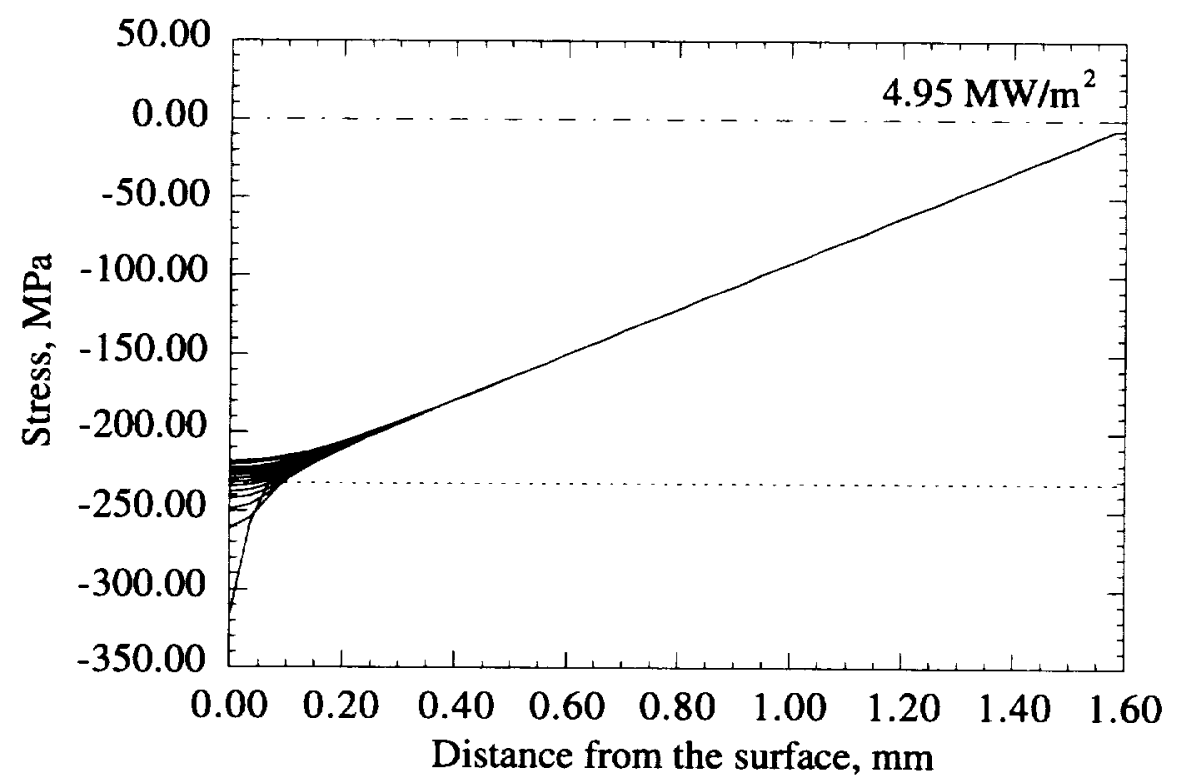

(a)

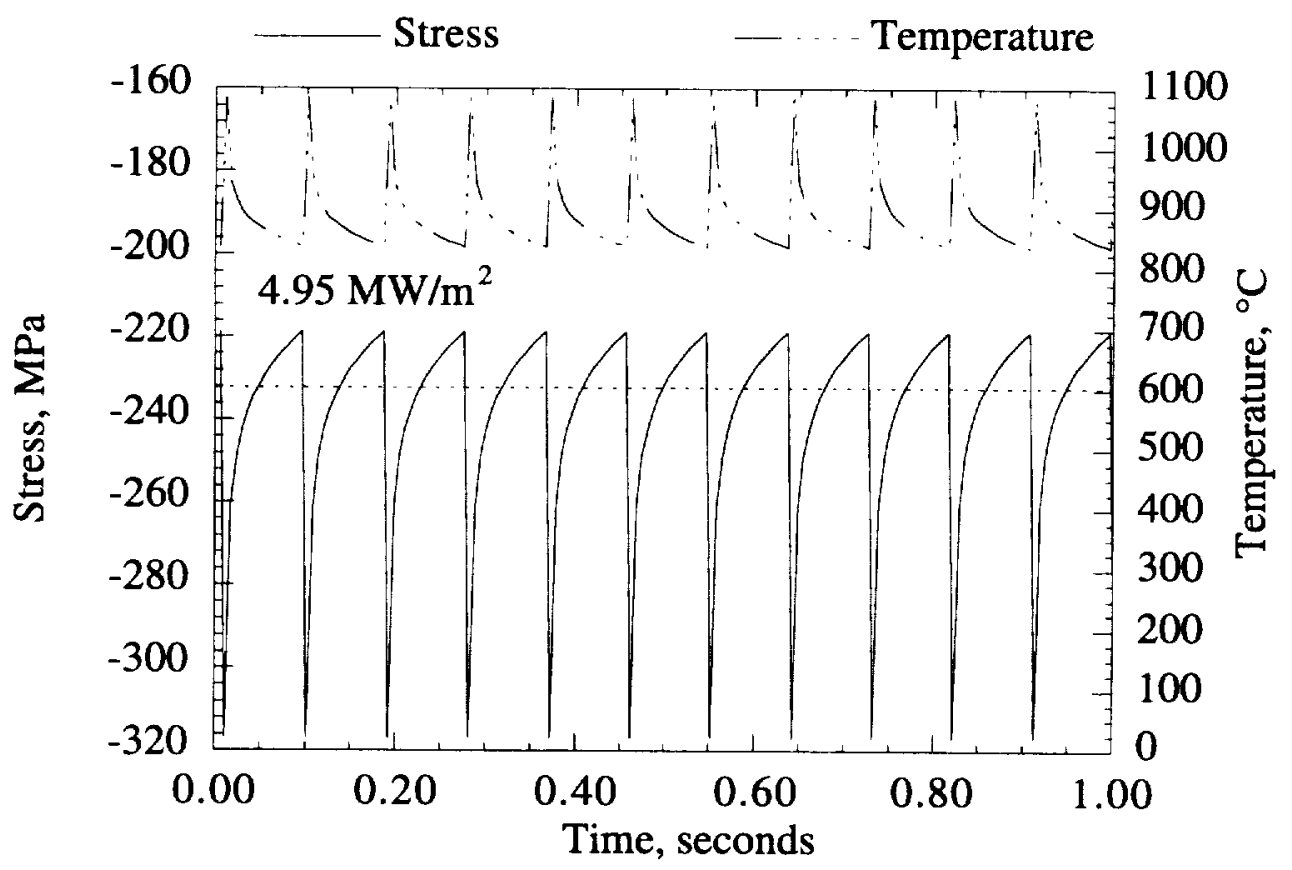

(b)

Fig. 3 Predicted stress distributions in the ceramic coating under pulsed laser heating conditions. The overall stress is the summation of the thermal stress and residual stress in the coating system (the compressive residual stress in the ceramic coating is assumed to be about $27 \mathrm{MPa}$ after processing). Besides a constant stress gradient generated by the steady state heating, high frequency HCF cyclic stresses are present near the ceramic coating surface. (a) Stress distributions in the ceramic coating; (b) HCF cyclic stress variations at the coating surface as a function of time. 


\section{EXPERIMENTAL RESULTS}

Surface cracking was observed for all specimens which were tested to a total heating time of 256 hours. Compared to the pure LCF tested specimen, the combined LCF/HCF tests produced higher crack densities. At the angle iron corners, nearly parallel cracks which run across the corners were formed. In contrast, equiaxial crack networks were generated by the laser tests at the rectangular specimen surfaces. At the edges of the rectangular specimens, parallel cracks similar to those found on the angle iron corners were observed with crack direction perpendicular to the edges. The general features of the fatigue cracking in the coating, however, are similar for both specimen configurations. The previous work has reported ${ }^{[10,13]}$ that the HCF component can initiate lateral crack branching and multiple delaminations under HCF bending moments along the inter-splat planes of weakness. Fig. 4 shows typical micrographs of the crack morphologies in the ceramic coating after the combined LCF/HCF testing. The HCF thermal loads resulted in severe surface damage. The deep vertical crack also induced lateral crack branching and delamination near the ceramic/bond interface.

Surface crack growth rates (the crack growth rates from the surface towards the interface) for the ceramic coatings under both LCF and LCF/HCF test conditions have been determined by measuring various crack lengths observed in single specimens after each test. Statistical analysis has been used to compare these results. As shown in Fig. 5, the measured crack length in the ceramic coating system increases with the LCF cycle number and surface temperature. The HCF component tends to increase the overall coating crack length, especially when crack branching is considered. It seems that the fatigue crack growth rate in the ceramic coating strongly depends on the characteristic HCF cycle number, $N_{H C F}^{*}$, which is defined as HCF cycle numbers per LCF cycle. As can be seen in Fig. 6, the average fatigue crack growth rate, based on crack depth in the coating, increases with the characteristic HCF cycle number. The crack growth rate is increased from $0.36 \mu \mathrm{m} / \mathrm{LCF}$ cycle for a pure LCF test $\left(N_{H C F}^{*}=0\right)$ to $1.8 \mu \mathrm{m} / \mathrm{LCF}$ cycle for a combined LCF and HCF test $\left(N_{H C F}^{*}=20,000\right)$, when the surface temperature $T_{s}$ is $850^{\circ} \mathrm{C}$. The crack growth rate is approximately $2.8 \mu \mathrm{m} / \mathrm{LCF}$ cycle when the surface temperature $T_{s}$ is $950^{\circ} \mathrm{C}$. The increased crack growth rate in the ceramic coating with characteristic cycle number may be attributed to the pure HCF interaction effect and increased sintering effect due to longer heating cycle or higher temperature. In the separate thermal shock tests which simulate the pure HCF process with an interaction depth of $0.3 \mathrm{~mm}$, the crack growth rates were about $0.18 \mu \mathrm{m} / \mathrm{HCF}$ cycle and $0.02 \mu \mathrm{m} / \mathrm{HCF}$ cycle for the temperature swings of $750^{\circ} \mathrm{C}$ and $420^{\circ} \mathrm{C}$, respectively. 


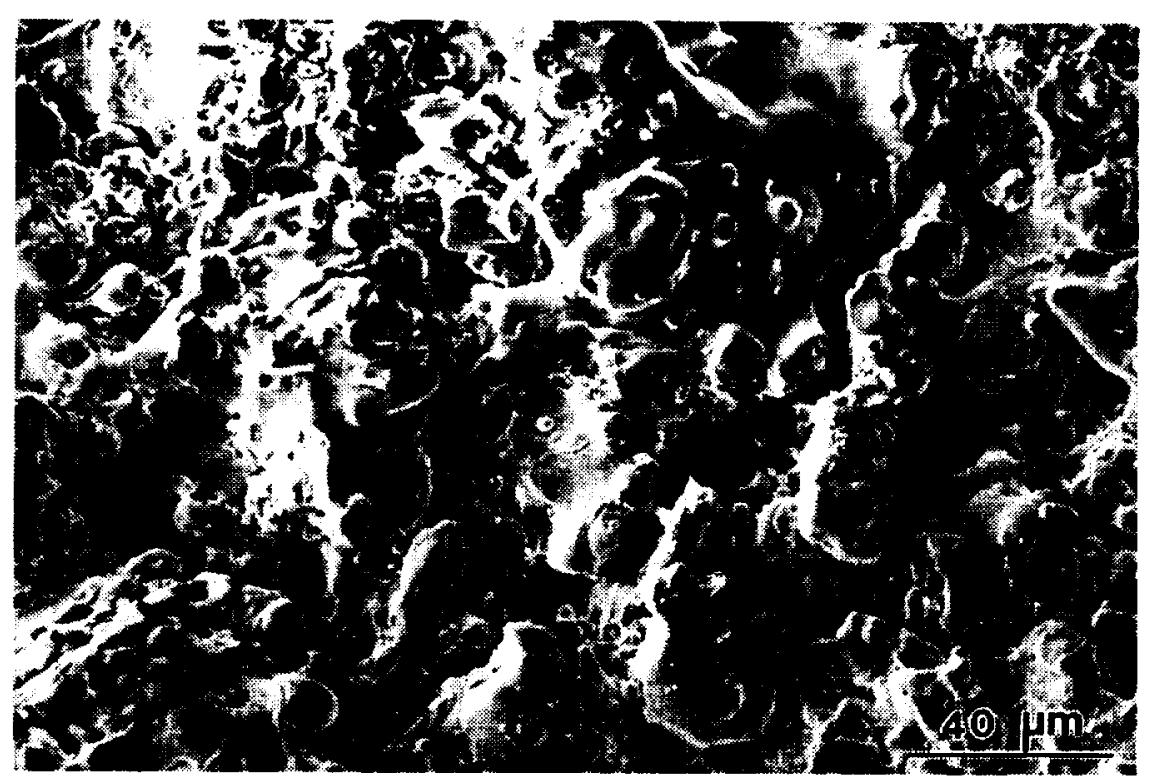

(a)

Fig. 4 Micrographs of the ceramic coating on the angle iron after the combined LCF and HCF testing (surface temperature $950^{\circ} \mathrm{C}, 30$ minute heating and 6 minute cooling cycle, 510 LCF cycles and $10 \times 10^{6} \mathrm{HCF}$ cycles). (a) SEM micrograph showing surface crack morphology; (b) and (c) Optical micrographs of the cross-section of the coating showing the severely damaged surface region, and the crack propagation and delamination at the ceramic/bond coat interface. 


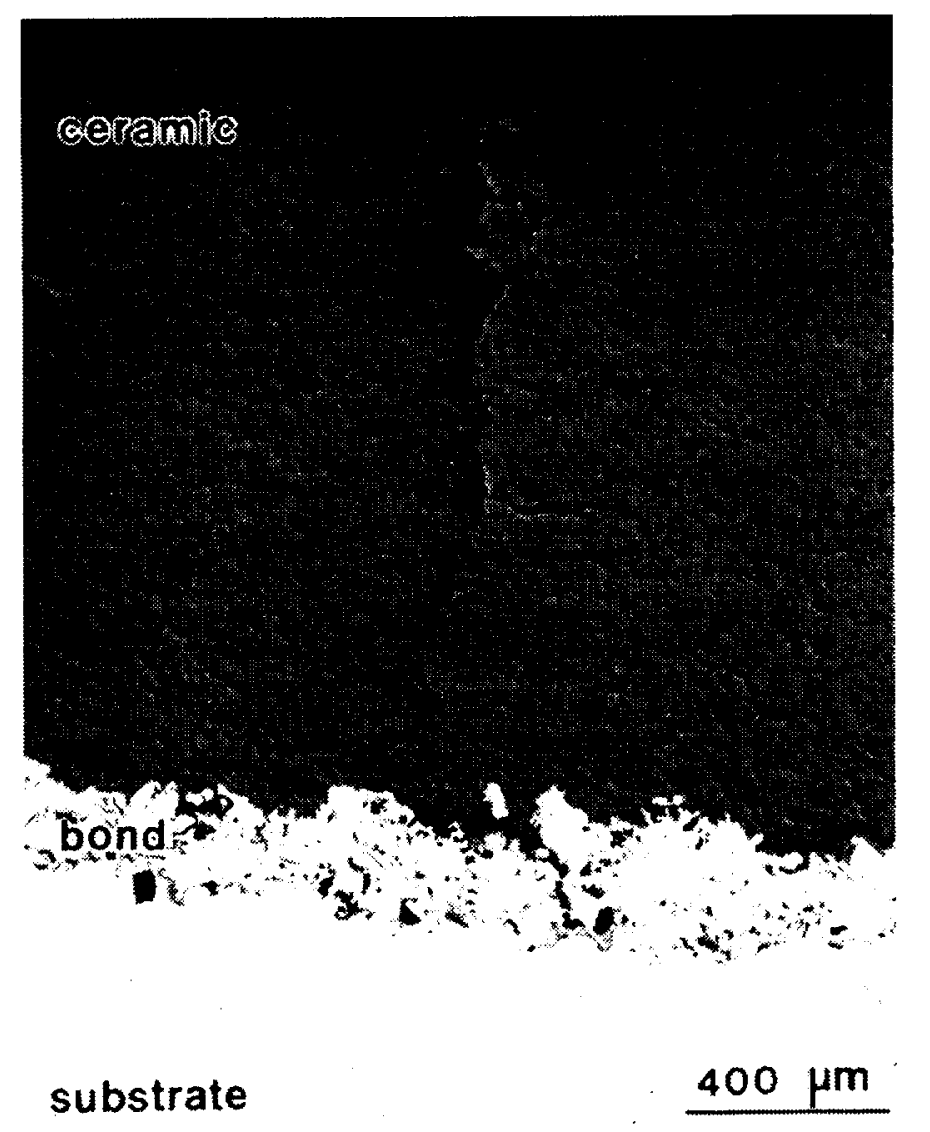

(b)

Fig. 4 (Continued) Micrographs of the ceramic coating on the angle iron after the combined LCF and HCF testing (surface temperature $950^{\circ} \mathrm{C}, 30$ minute heating and 6 minute cooling cycle, $510 \mathrm{LCF}$ cycles and $10 \times 10^{6} \mathrm{HCF}$ cycles). (a) SEM micrograph showing surface crack morphology; (b) and (c) Optical micrographs of the crosssection of the coating showing the severely damaged surface region, and the crack propagation and delamination at the ceramic/bond coat interface. 


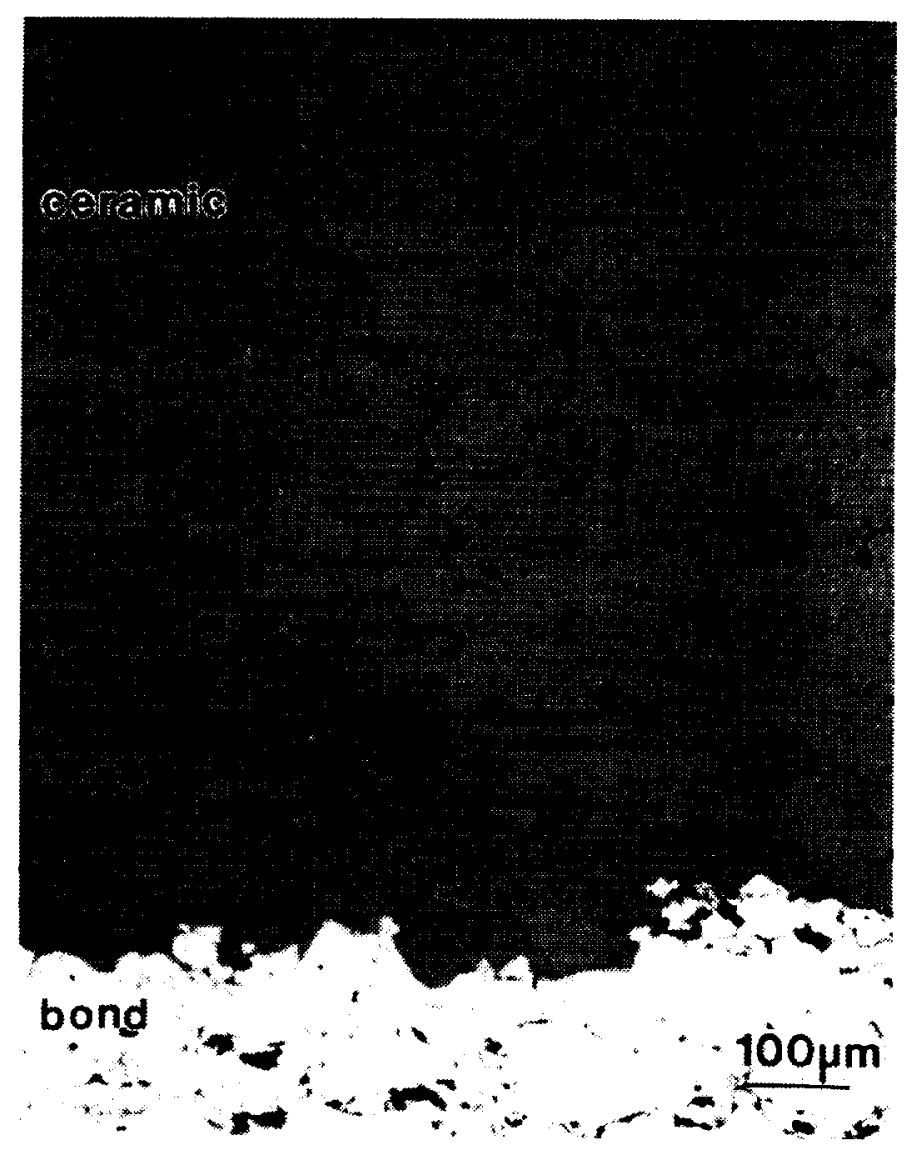

(c)

Fig. 4 (Continued) Micrographs of the ceramic coating on the angle iron after the combined LCF and HCF testing (surface temperature $950^{\circ} \mathrm{C}, 30$ minute heating and 6 minute cooling cycle, $510 \mathrm{LCF}$ cycles and $10 \times 10^{6} \mathrm{HCF}$ cycles). (a) SEM micrograph showing surface crack morphology; (b) and (c) Optical micrographs of the crosssection of the coating showing the severely damaged surface region, and the crack propagation and delamination at the ceramic/bond coat interface. 


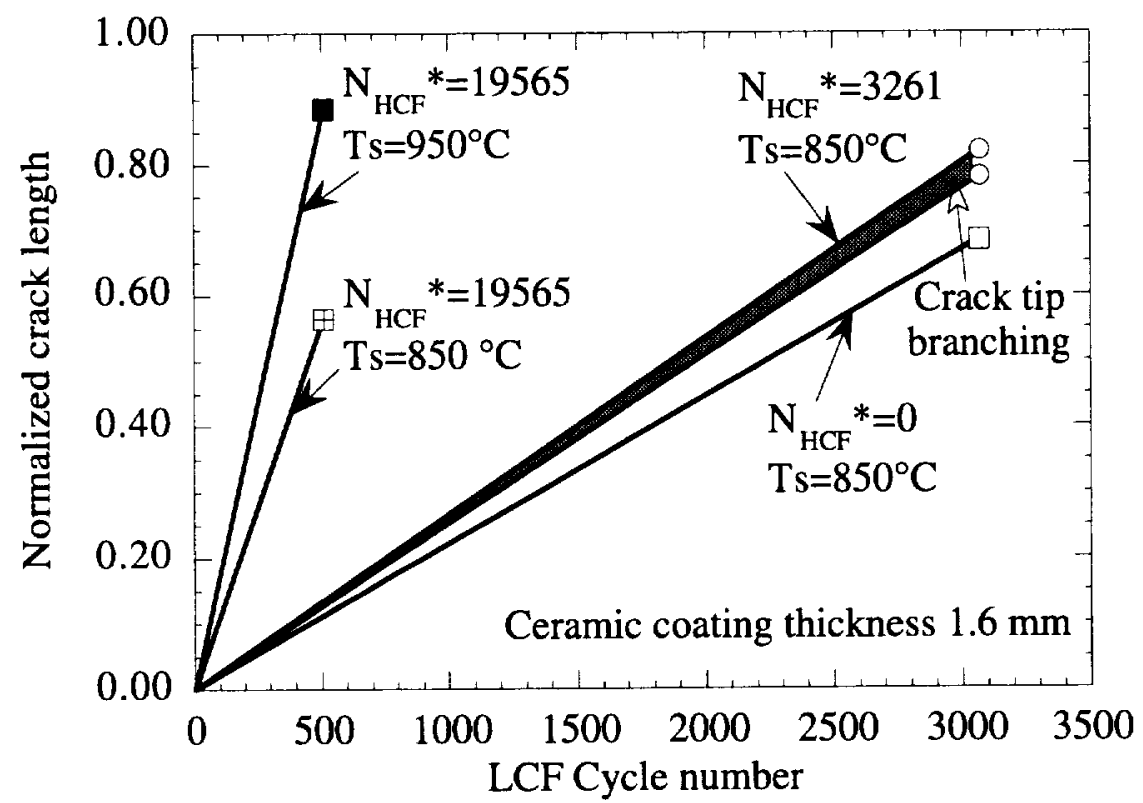

Fig. 5 The crack length (normalized to the coating thickness) as functions of LCF and characteristic HCF numbers. For given LCF and HCF cycle numbers, longer crack length was obtained at surface temperature $950^{\circ} \mathrm{C}$ as compared at $850^{\circ} \mathrm{C}$. The crack growth rates with respect to LCF cycle is assumed to be linear under various LCF and HCF test conditions, and therefore is represented by the slopes of these straight lines.

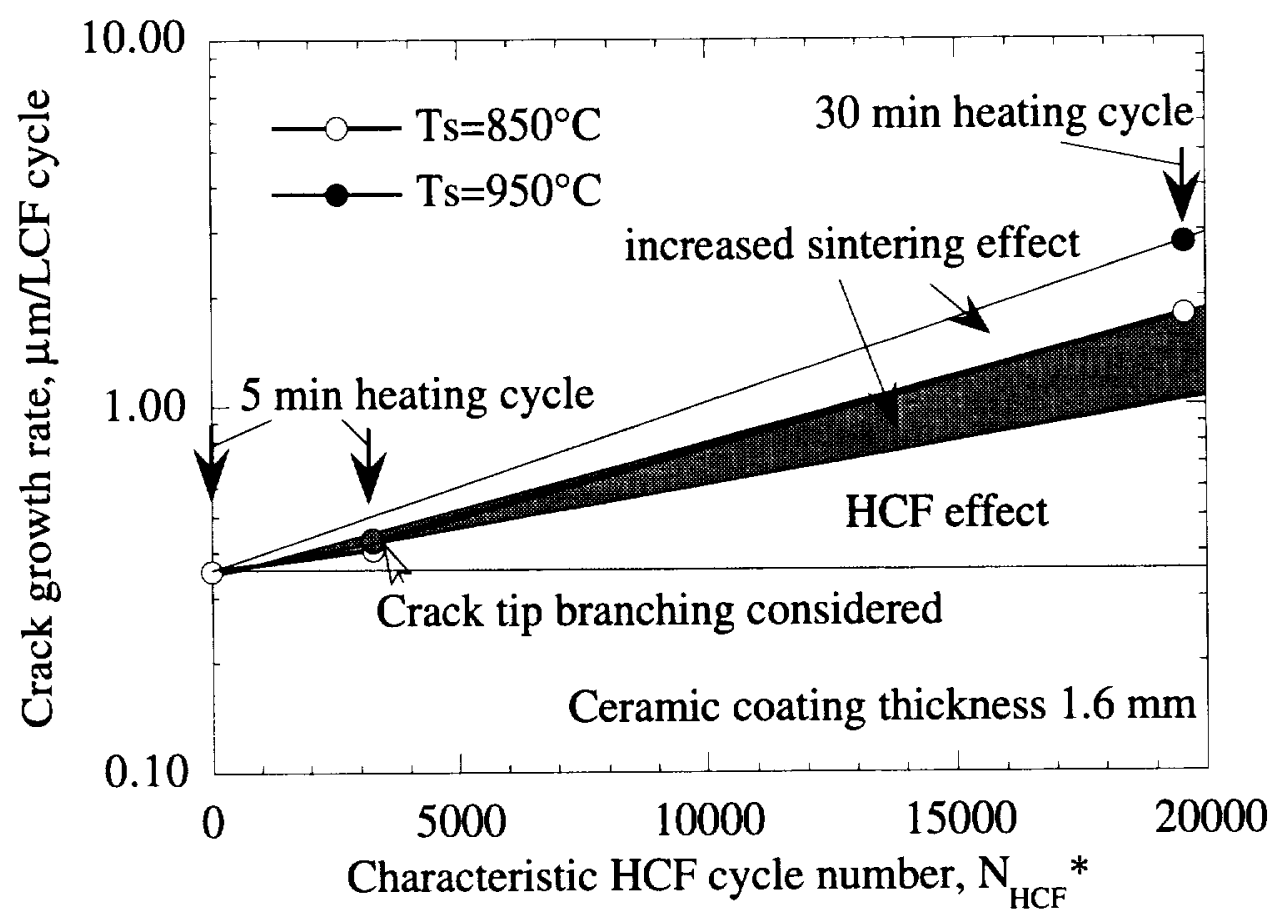

Fig. 6 Crack growth rate as a function of characteristic HCF cycle number (HCF numbers per LCF cycle), $N_{H C F}^{*}$. With the fixed HCF frequency, the increased crack growth rate in the ceramic coating with characteristic cycle number is attributed to the pure HCF interaction effect and increased sintering effect due to longer heating cycle or higher temperature. 


\section{DISCUSSION}

The experiments demonstrate strong interactions between LCF, HCF and ceramic coating creep. It is known that in plasma-sprayed $\mathrm{ZrO}_{2}-\mathrm{Y}_{2} \mathrm{O}_{3}$ ceramic coatings, the primary creep stage is significant due to the porous and microcracked nature of these coatings ${ }^{[15-17]}$. This creep behavior is probably related to stress-enhanced ceramic sintering, splat sliding, and the stress redistribution around the splats and microcracks. The time and stress-dependent deformation can result in coating shrinkage and thus stress relaxation at temperature under the compressive stresses. The strain rate $\dot{\varepsilon}_{p}$ can be generally written as

$$
\dot{\varepsilon}_{p}^{i}=A \cdot \exp \left(-\frac{Q}{R T}\right) \cdot\left(\sigma_{t h}^{0}-\varepsilon_{p}^{i-1} \frac{E_{c}}{1-v_{c}}\right)^{n} \cdot t_{i}{ }^{-s}
$$

where $\dot{\varepsilon}_{p}^{i}$ and $\varepsilon_{p}{ }^{i-1}$ are the creep strain rate at time $t_{i}$, and the total accumulated strain at the previous time step $t_{i-1}$, respectively, $A, n$ and $s$ are constants, $Q$ is the activation energy, $T$ is temperature, $R$ is the gas constant, $\sigma_{t h}^{0}$ is the initial thermal stress in the coating, and $E_{c}$ and $v_{c}$ are the elastic modulus and Poisson's ratio of the ceramic coating. The stress relaxation effect on the creep strain rate is accounted for by the $\varepsilon_{p}{ }^{i-1}$ term in Equation (1). The total creep strain, with stress relaxation considered in the coating, can thus be expressed as ${ }^{[17]}$

$$
\varepsilon_{p}=\left\{\sigma_{0}-\left[\sigma_{0}^{1-n}-A \cdot \frac{E_{c}(1-n)}{\left(1-v_{c}\right)(1-s)} \cdot \exp \left(-\frac{Q}{R T}\right) \cdot t^{1-s}\right]^{\frac{1}{1-n}}\right\} \cdot \frac{1-v_{c}}{E_{c}}
$$

For the purpose of demonstration, the modeling for the creep strain and stress calculations in this paper, has been assumed a coating modulus value representing of the as-processed coating. The significant change in coating modulus that may be experienced during service will be addressed in future publications by the present authors ${ }^{[17]}$. Fig. 7 illustrates the modeled coating creep strains in the ceramic coating as a function of coating depth at various times with different coating creep constants. It can be seen that the creep behavior of the coating exerts a significant influence on the shrinkage strains. 


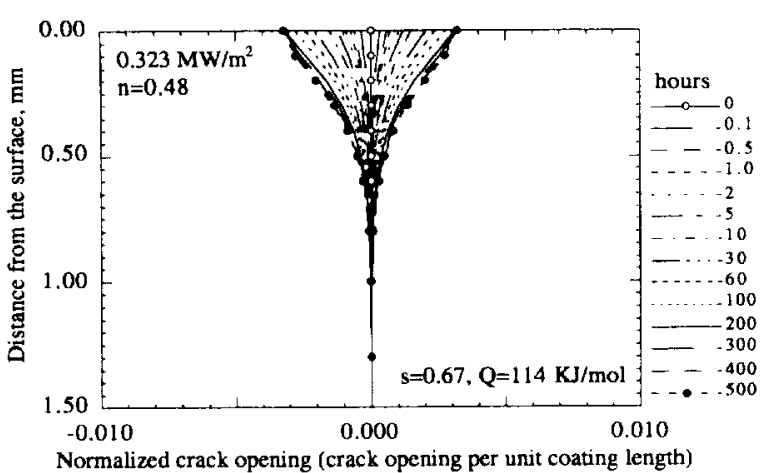

(a)

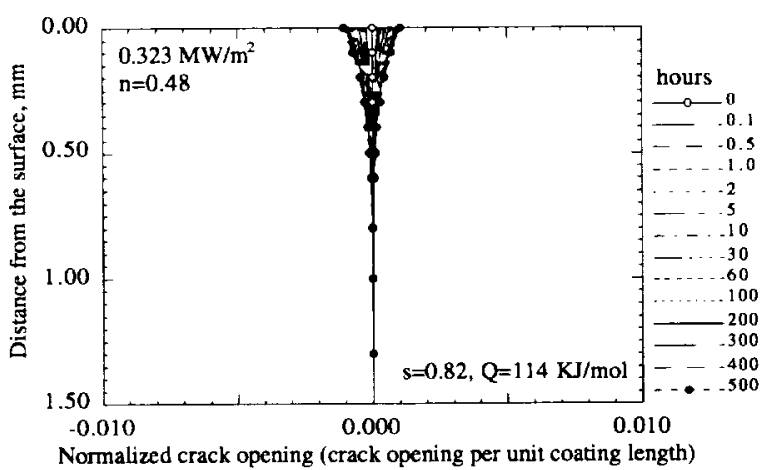

(c)

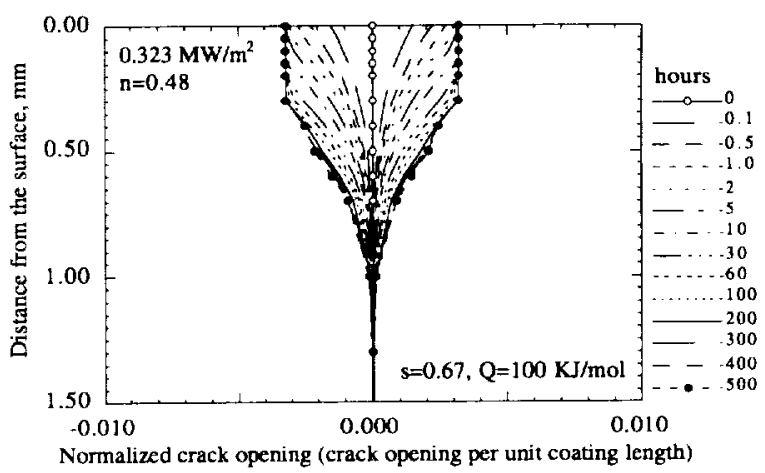

(b)

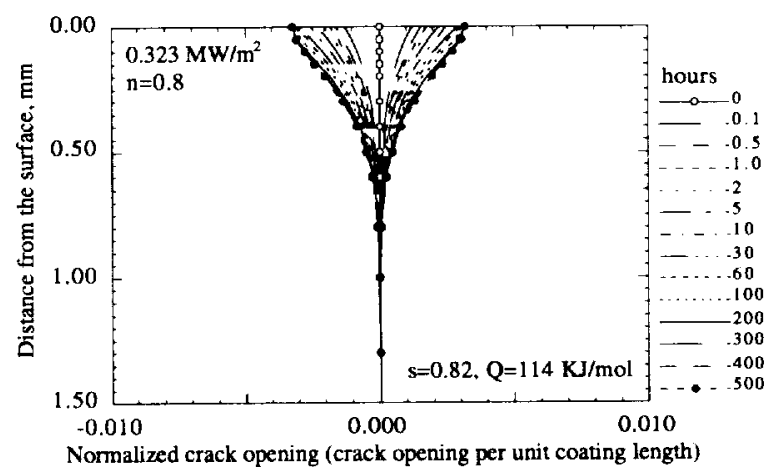

(d)

Fig. 7 Simulated coating creep strains as a function of coating depth at various times (constant ceramic coating modulus $27.6 \mathrm{GPa}$, ceramic surface temperature $872^{\circ} \mathrm{C}$, n stress exponent, s time exponent, and $Q$ activation energy). The creep strains will induce tensile stresses in the coating during cooling. 
The pulsed laser induced temperature swing can generate high compressive stresses that can result in the coating surface fracture. More importantly, the surface tensile stress, mainly generated by coating shrinkage due to coating sintering and creep at temperature, could also induce cracking during cooling. Fig. 8 shows that for a given heat flux and average surface temperature, the HCF component will generate a considerably higher creep rate at the coating surface compared to the pure LCF mode. Since the laser HCF component will promote both coating surface creep and surface compressive cracking, accelerated crack initiation and higher surface crack density at the coating surfaces are expected, as confirmed by this experiment.

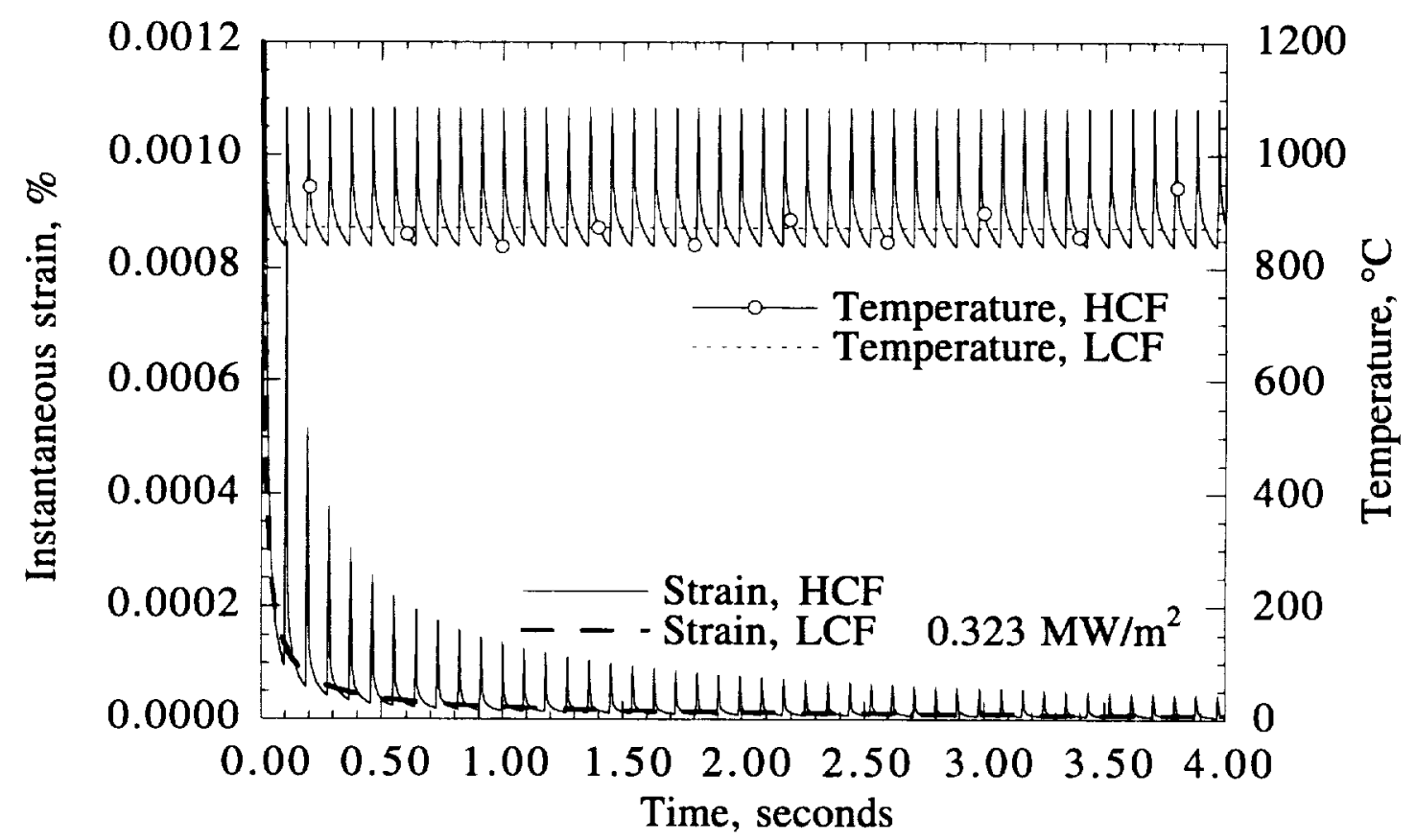

Fig. 8 Predicted instantaneous creep strains under LCF and HCF conditions (stress and time exponents are 0.48 and 0.82 respectively, activation energy $114 \mathrm{KJ} / \mathrm{mol}$ ) 
Under the conditions of the low ceramic/metal interfacial temperatures in this study, the oxidation of bond coat and substrate is not important. The thermal expansion mismatch between the ceramic coating and bond coat is also minimized at the low temperatures even in non-graded coatings. Therefore, the LCF mechanism in the thick thermal barrier coatings is closely associated with the coating sintering and creep at high temperature. These creep strains in the ceramic coating will lead to a tensile stress state during cooling, thus providing the major driving force for the crack growth under LCF conditions. On the other hand, the HCF is closely associated with the cyclic stresses originating from the high frequency temperature fluctuation at the ceramic coating surface. The HCF thermal loads act on the crack by a wedging mechanism ${ }^{[12]}$, resulting in the continuous crack growth at temperature. As shown in Fig. 9, the HCF stress intensity factor amplitude predicted by this model increases with increasing the interaction depth and temperature swing, and decreases with increasing the crack depth. The HCF damage effect also increases with increasing the thermal expansion coefficient and Young's modulus of the ceramic coating ${ }^{[12]}$. It should be noted that, depending on the coating stress state at high temperature, the HCF may affect crack propagation far beyond the laser interaction depth. This has been demonstrated experimentally in pure HCF cycling where high temperature swings were generated near the surface of the ceramic coating ${ }^{[13]}$. In the present case, the high surface thermal loads resulted in significantly higher crack growth rate. 


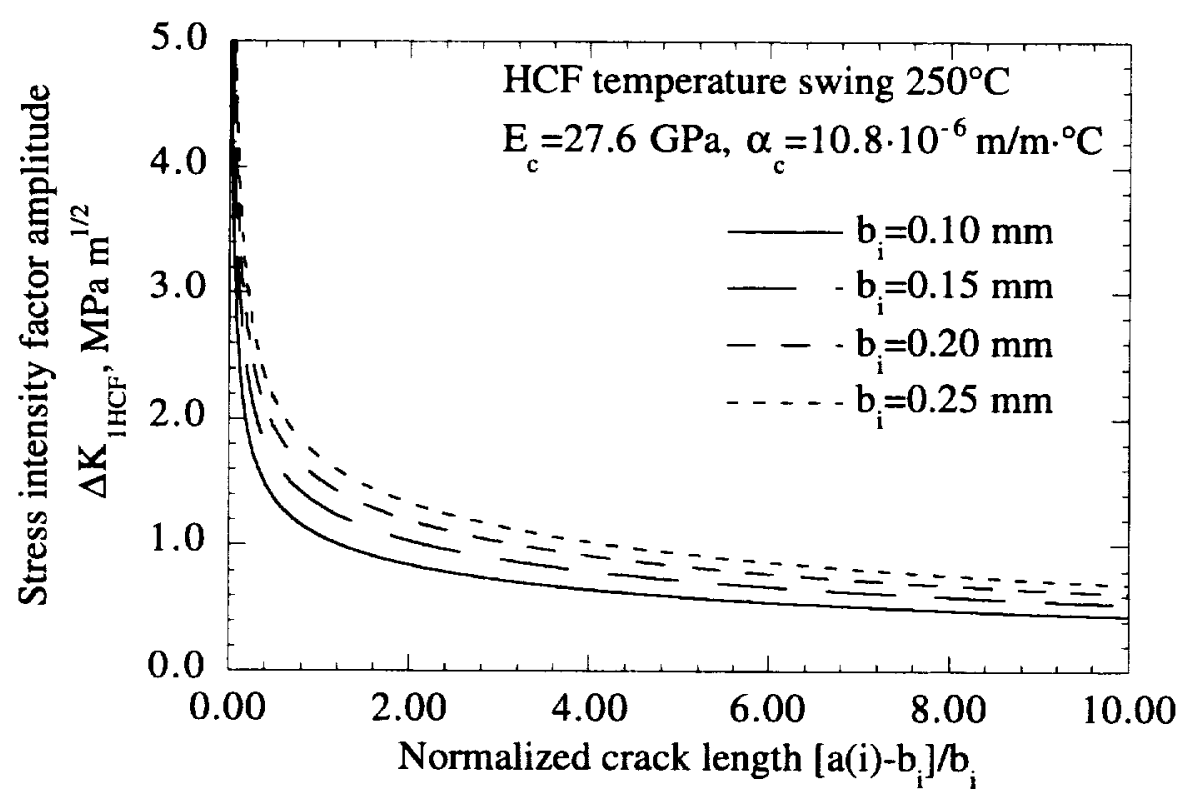

(a)

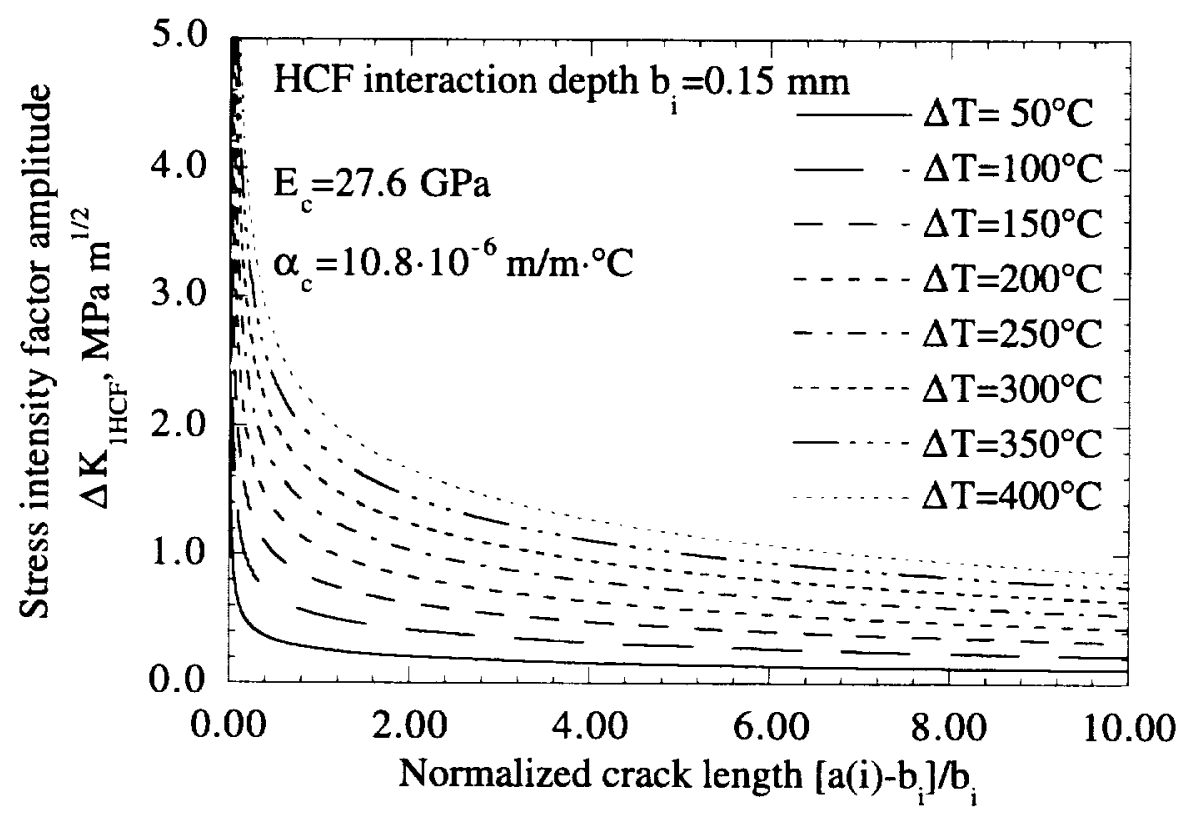

(b)

Fig. 9 The HCF stress intensity factor amplitude as a function of normalized crack length. (a) The influence of interaction depth on the HCF stress intensity factor amplitude; (b) The influence of temperature swing on the HCF stress intensity factor amplitude. 
The LCF/HCF interactions are expected to be complex. As illustrated in Fig. 10 for the proposed LCF/HCF mechanisms, alternating HCF and LCF loading at temperature and during cooling would increase the overall crack growth rate in the combined LCF/HCF tests. The relative magnitudes of the LCF and HCF components for crack propagation depend on the time, the crack length and the crack tip location within the coating, because the LCF and HCF stress intensity factor amplitudes are expected to vary with these parameters, as will be discussed in the Appendix. Fig. 11 shows examples of the LCF stress distributions after cooling in the coating system. It can be seen that in general, the tensile stresses in the coating are highest at the surface, and increase with cycle time. Fig. 12 illustrates the estimated HCF and LCF stress intensity factor amplitudes as a function of coating depth at various times. The results indicate that the HCF dominates initially, especially near the surface region, whereas the LCF prevails for longer times and greater depths. It is also noted that, due to the ceramic-bond coat elastic mismatch, the stress intensity factor amplitudes tend to drop to zero when the crack approaches the ceramic/bond coat interface because of the relatively stiff bond coat. This asymptotic behavior of the stress intensity factor amplitudes near the ceramic/bond coat interface under the present LCF and HCF loading conditions, as shown in Fig. 12, is obtained by invoking the Zak-Williams singularity at the interface, using the approach described in literature ${ }^{[18]}$. Therefore, the crack will be expected to deflect along the interface, thus leading to interface delamination under subsequent $\mathrm{LCF}$ and HCF loading. The delamination phenomena due to vertical cracks in the ceramic coatings have often been observed in the experiments ${ }^{[6]}$.

The thermal LCF and HCF crack growth is also greatly influenced by the HCF loadingunloading process. The HCF cyclic loading and bending moments on the coating could cause extensive relative displacements at the crack wake surfaces, thus generating extensive crack branching and multiple delaminations by asperities/debris contact cracking and splat pull-out bending mechanisms. The stresses induced locally by these crack wake interactions could also accelerate the major crack propagation even during the LCF and HCF unloading stage. The surface HCF thermal loads will exert profound but detrimental influences on the coating thermal fatigue resistance. 


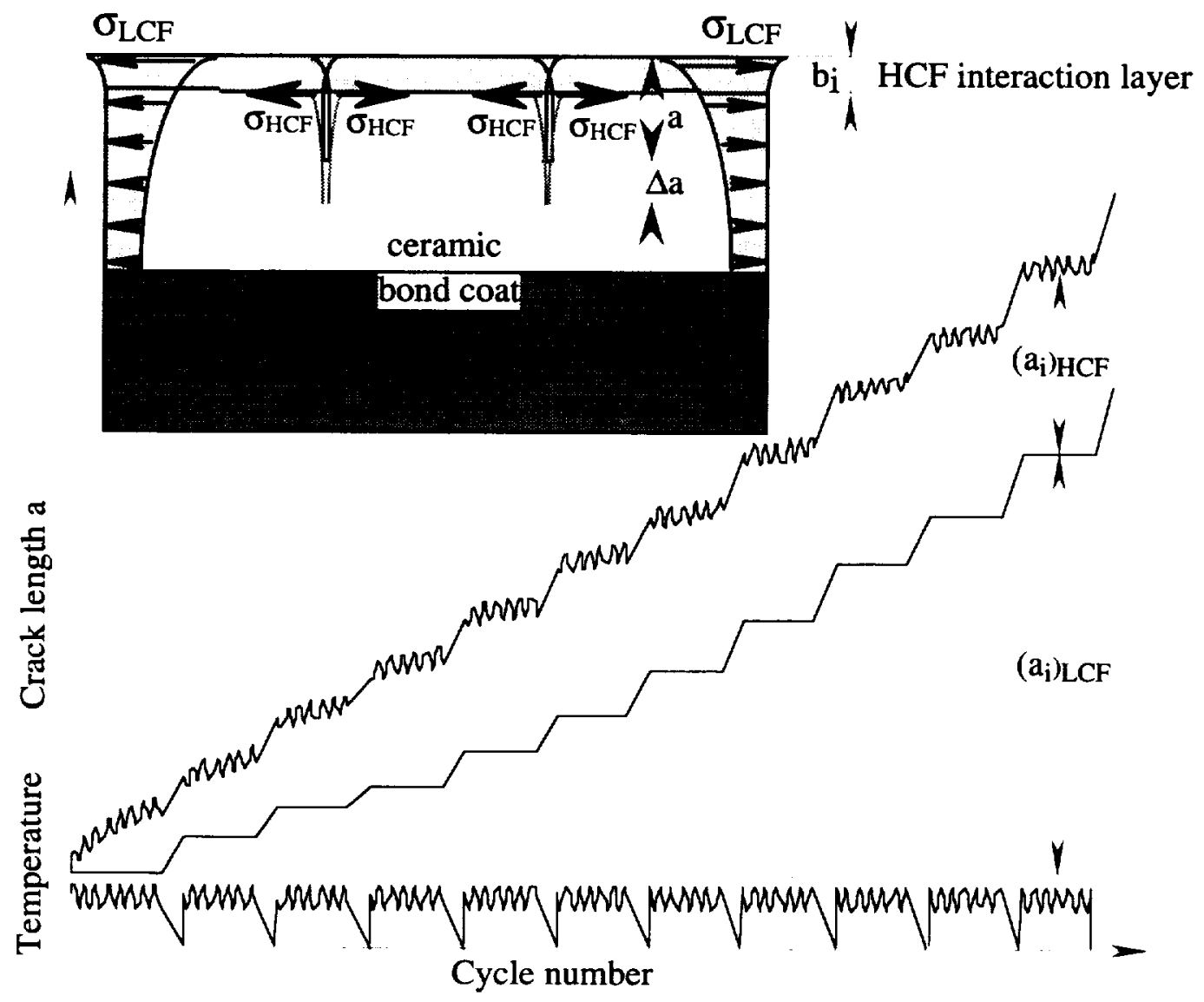

Fig. 10 Schematic diagram showing LCF and HCF mechanisms. 


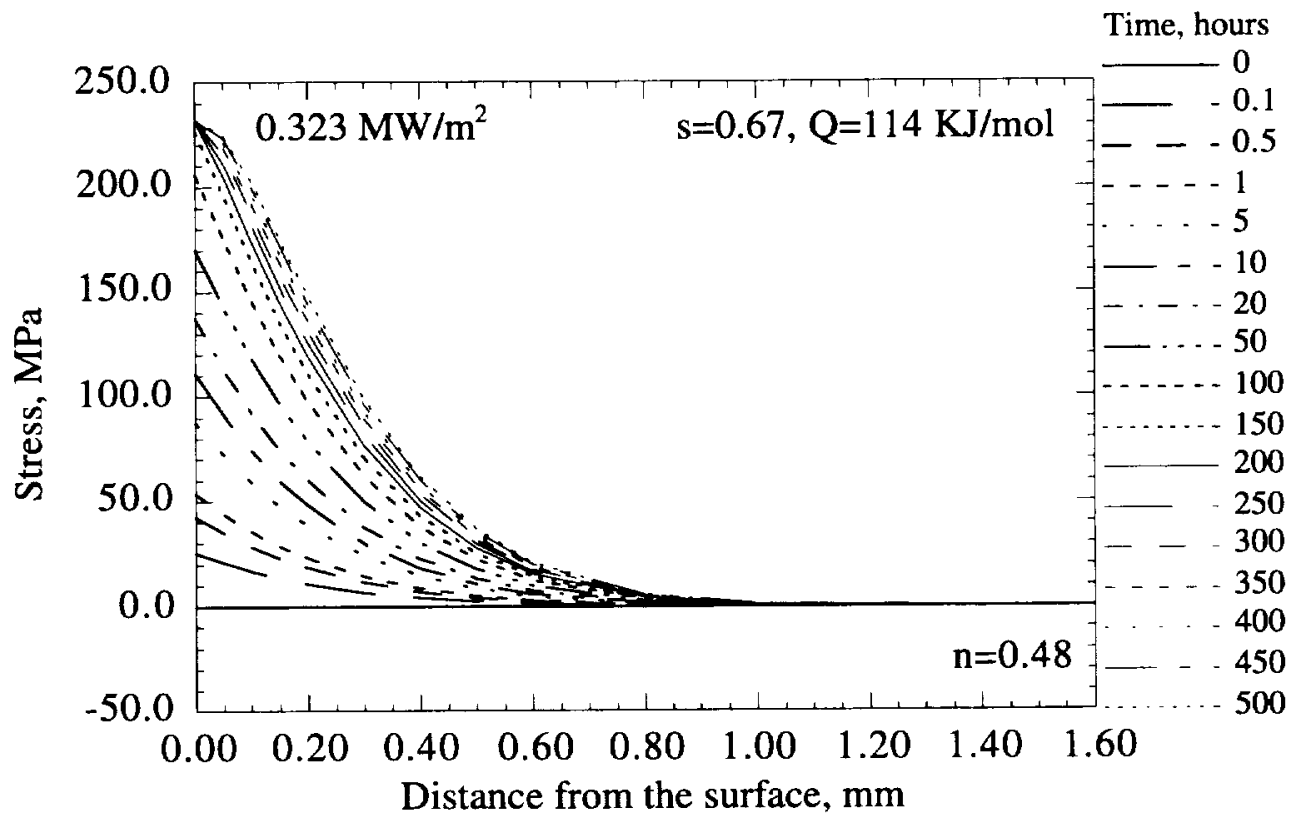

Fig. 11 Tensile stresses generated in the ceramic coating during cooling as a function of time and coating layer depth. The stresses are highest at the surface and increase with time.

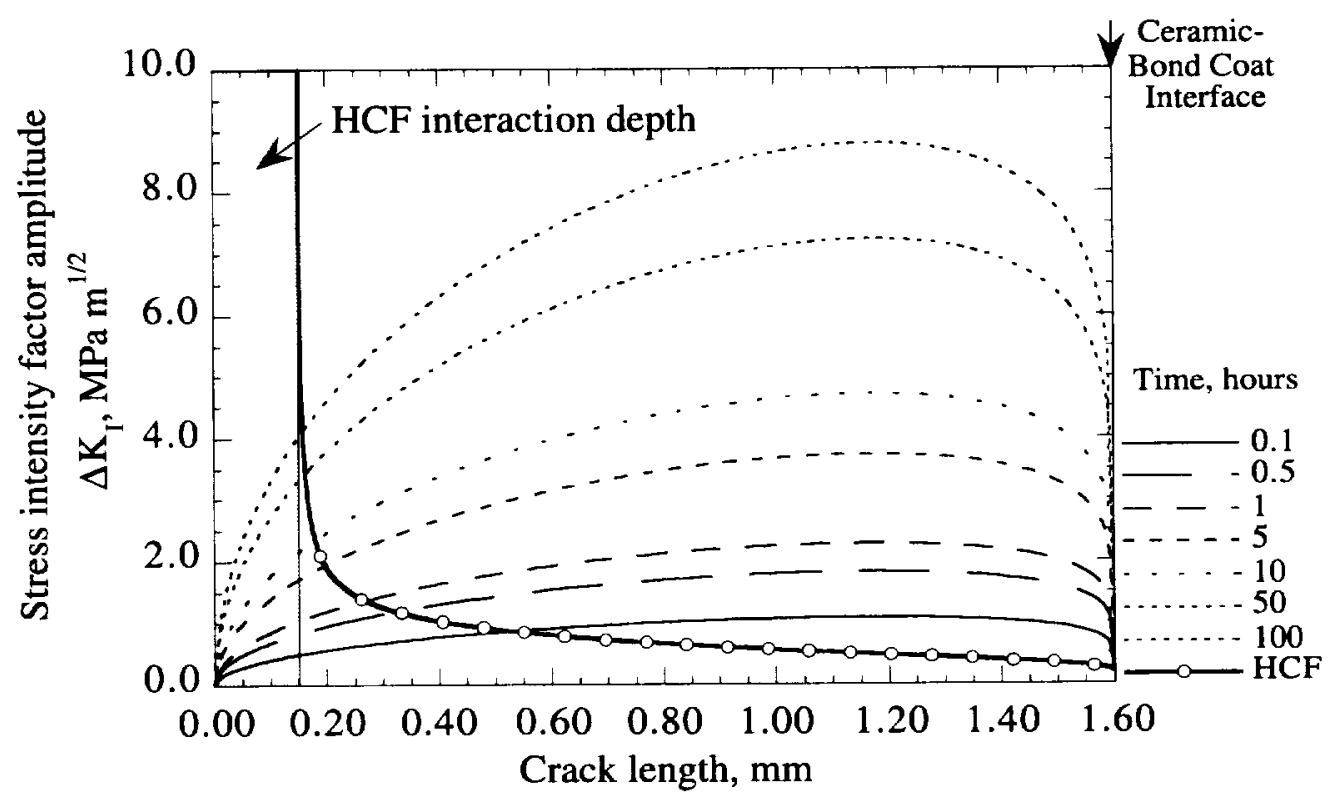

Fig. 12 The variations of mode I stress intensity amplitudes of the vertical crack in the coating as a function of coating depth showing the relative importance of the HCF and LCF components on the crack growth. The HCF has greater relative importance at short time and short crack length. 


\section{CONCLUSIONS}

This paper presents a detailed analysis concerning mechanisms of fatigue crack initiation and propagation, and coating delamination under high heat flux thermal cycling conditions. The coating creep and fatigue interactions are also described based on experimental evidence. The results obtained from the laser thermal fatigue tests help to better understand the thermal fatigue processes of the coating system.

It was found that surface cracks in the ceramic coating initiate and propagate continuously under complex thermal low cycle and high cycle fatigue stresses. Due to the ceramic-bond coat elastic mismatch, these vertical cracks can deflect along the ceramic/bond coat interface, thus eventually leading to coating delamination under subsequent LCF and HCF loading. The failure mechanism associated with LCF is closely related to coating sintering and creep at high temperatures. The creep strains that are developed at high temperature induce tensile stresses in the ceramic coating during cooling, thus providing the major driving force for the crack growth under LCF conditions. The failure mechanism associated with HCF is mainly related to the cyclic stresses originating from the high frequency temperature fluctuation, as described by a surface wedging process.

The combined LCF/HCF tests tend to generate more severe coating surface cracking, microspallation and accelerated crack growth, than the pure LCF test. Lateral crack branching and the ceramic/bond coat interface delamination can also be facilitated by HCF thermal loads, even in the absence of severe interfacial oxidation. The increased HCF damage phenomena are attributed to the enhanced surface sintering and crack initiation, the surface wedging and increased loadingunloading fatigue damage at crack wake surfaces.

The relative magnitudes of the LCF and HCF components for crack propagation depend on the time, the crack length and the crack tip location within the ceramic coating. The HCF effect dominates initially, especially near the surface region, whereas the LCF effect prevails for longer times and greater depths. The profound interactions between LCF, HCF and ceramic coating creep are observed from the crack propagation kinetics under various test conditions. 


\section{ACKNOWLEDGMENTS}

This work was performed while the first author held a National Research Council-NASA Lewis Research Center Research Associateship partially supported by the Army Research Laboratory. The authors are indebted to M. Brad Beardsley, Caterpillar Inc., for valuable discussions. The authors are grateful to George W. Leissler for his assistance in the preparation of TBC coatings.

\section{APPENDIX STRESS INTENSITY FACTOR AMPLITUDES OF THERMAL HIGH CYCLE FATIGUE AND LOW CYCLE FATIGUE}

During a superimposed thermal LCF/HCF testing, the surface vertical crack in the thick thermal barrier coating can propagate under both LCF and HCF loads. The crack growth rate with respect to LCF cycle number can be generally expressed as ${ }^{[12]}$

$$
\left(\frac{d a}{d N}\right)_{L C F}=C_{1}\left(\Delta K_{\mathrm{I} L C F}\right)^{m}+\int_{0}^{N_{H C F}^{*}} C_{2}\left(\Delta K_{\mathrm{I} H C F}\right)^{m} d N_{H C F}
$$

where $m, C_{1}$ and $C_{2}$ are constants, $N_{H C F}^{*}$ is the characteristic HCF number, $\Delta K_{\mathrm{LCF}}$ and $\triangle K_{1 H C F}$ are stress intensity factor amplitudes of the crack under LCF and HCF loads, respectively. The stress intensity factor amplitudes are functions of crack geometry, crack length, stress magnitudes and distributions. It can be seen from Equation (A1) that the crack propagation rate depends not only on coating properties, but also on LCF and HCF parameters which define stress states and fatigue mechanisms.

The Low Cycle Fatigue Stress Intensity Factor Amplitude

The mode I stress intensity factor amplitude for LCF crack growth can be generally written as ${ }^{[12]}$

$$
\Delta K_{L C F}=Y \cdot\left[\sigma_{L C F}-\sigma_{t h}\right] \cdot \sqrt{\pi \cdot a(i)}
$$

where $Y$ is a geometry factor related to the crack configuration, for a surface crack, $Y=1.1215$. $\sigma_{t h}$ and $\sigma_{L C F}$ are the thermal stress at temperature and LCF stress during cooling in the coating. 
The compressive thermal stress will relax extensively with time, especially near the surface high stress and temperature region ${ }^{[12,13]}$. In contrast, the tensile LCF stress, which is associated with the time dependent, non-elastic strains in the ceramic coating at temperature, will increase with time. To a first approximation, the LCF stress under the assumed biaxial stress condition after cooling can be written as

$$
\sigma_{L C F}=\varepsilon_{p}\left(\sigma_{t h}, T, t\right) \cdot \frac{E_{c}}{1-v_{c}}
$$

where $\varepsilon_{p}\left(\sigma_{t h}, T, t\right)$ is the total accumulated creep strain in the ceramic coating, as has been described previously by Equation (2). The bond coat and metal substrate creep is not considered because of the low temperatures at the interfaces during the thermal fatigue testing. Examples of LCF stresses as a function of time and coating depth for a coating system has been illustrated in Fig. 11. Assuming that the crack does not grow under the compressive thermal stress $\sigma_{t h}$, the stress intensity will depend primarily on $\sigma_{L C F}$ and the crack length $a(i)$. Therefore, the LCF crack growth rate will increase with time, because the LCF stress level and the crack length increase with time.

The estimation of the stress intensity factor amplitude associated with the LCF process is complex. The LCF stress, which has a considerable distribution across the coating, changes with time. In addition, the stress intensity factor amplitude of the fatigue crack will significantly deviate from the surface crack solution when the crack has a comparable length with the coating thickness, especially when the crack approaches the ceramic/bond coat interface. The elastic mismatch at the interface for the vertical crack can be taken into account by invoking the ZakWilliams singularity to the regular stress intensity factor ${ }^{[18]}$. The stress distributions in the coating on a fatigue crack can be considered as distributed wedge forces over the crack, as shown in Fig. A1. The surface crack stress intensity factor, therefore, can be obtained from an integration over the crack under these wedge forces ${ }^{[19]}$. The LCF stress intensity factor amplitude thus can be written as

$$
\Delta K_{\mathrm{ILCF}}=\frac{1.1215 \cdot f(a(i), \alpha, \beta)}{\sqrt{\pi \cdot a(i)}} \cdot \int_{-a(i)}^{a(i)} \sigma(x) \cdot \sqrt{\frac{a(i)-x}{a(i)+x}} \cdot d x
$$

where number 1.1215 is the coefficient for a surface crack, $\sigma(x)$ is the stress distribution function, $f(a(i), \alpha, \beta)$ is a coefficient describing the interface singularity due to the elastic mismatch, which depends on the crack length, and Dundurs' parameters $\alpha$ and $\beta$. The coefficient $f(a(i), \alpha, \beta)$ can be expressed as ${ }^{[18]}$ 


$$
f(a(i), \alpha, \beta)=\left(\frac{a(i)}{h}\right)^{1 / 2}\left(1-\frac{a(i)}{h}\right)^{1 / 2-u}\left(1+\lambda \frac{a(i)}{h}\right)
$$

where $h$ is the coating thickness, $\lambda$ is a fitting parameter, $u$ is the singularity exponent depending on the elastic mismatch that is the root to the equation

$$
\cos (u \pi)-2 \frac{\alpha-\beta}{1-\beta}(1-u)^{2}+\frac{\alpha-\beta^{2}}{1-\beta^{2}}=0
$$

For the particular $\mathrm{ZrO}_{2}-8 \mathrm{wt} . \% \mathrm{Y}_{2} \mathrm{O}_{3}$ ceramic coating/FeCrAlY bond coat system, the parameters in Equations (A5) and (A6) have been calculated ${ }^{[6]}$. With Dundurs' parameters $\alpha=-0.67, \beta=-0.25, u$ is calculated from Equation (A6), and $u=0.338$. The fitting parameter $\lambda$ is obtained from the reference ${ }^{[18]}$ graphically based on the Dundurs' parameters, and $\lambda=-0.07$.

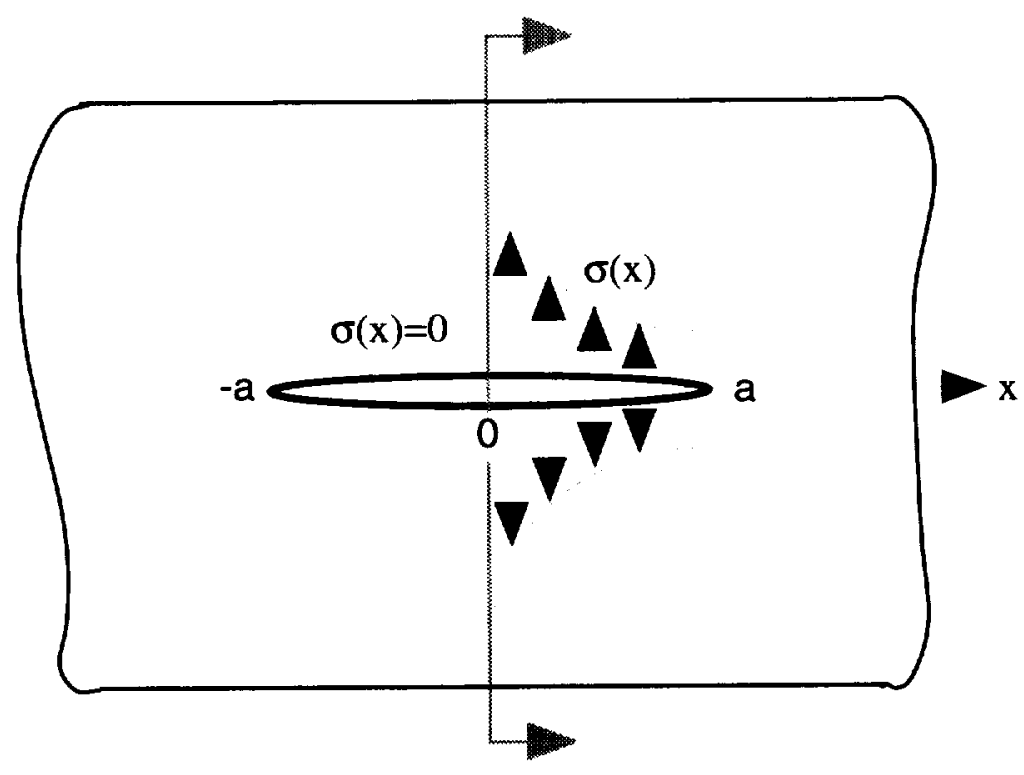

Fig. A1 Schematic diagram showing the determination of LCF stress intensity factor amplitude by the integration method for the distributed wedge forces over the crack. 


\section{High Cycle Fatigue Stress Intensity Factor Amplitude}

The high cycle fatigue is associated with the cyclic stresses resulting from the high frequency temperature fluctuation at the ceramic coating surface. This wedging process provides an intrinsic mechanism for the HCF phenomenon. Since the minimum HCF stress intensity factor equals zero, the net mode I stress intensity amplitude for this case can be expressed as $[12,20]$

$$
\Delta K_{\mathrm{I} H C F}=\frac{2 \cdot P \cdot f(a(i), \alpha, \beta)}{\pi} \frac{1+f_{H C F}(i)}{\sqrt{a(i)^{2}-b_{i}^{2}}} \sqrt{\pi \cdot a(i)}
$$

and

$$
P=\sigma_{H C F} \cdot b_{i}
$$

where $P$ is a concentrated load per unit thickness acting on the crack, $b_{i}$ is the load acting distance from the surface which is taken as laser interaction depth in the present study. Note that the interface singularity coefficient is also incorporated into Equation (7a). $\sigma_{H C F}$ is the HCF stress, $a(i)$ is the crack length at the ith cycle. $f_{H C F}(i)$ is a geometry factor, which can be related to the crack length $a(i)$ and the interaction depth $b_{i}$ in the following form ${ }^{[20]}$

$$
\begin{gathered}
f_{H C F}(i)=\left[1-\left(\frac{b_{i}}{a(i)}\right)^{2}\right] \cdot\left[0.2945-0.3912 \cdot\left(\frac{b_{i}}{a(i)}\right)^{2}+0.7685 \cdot\left(\frac{b_{i}}{a(i)}\right)^{4}\right. \\
\left.-0.9942 \cdot\left(\frac{b_{i}}{a(i)}\right)^{6}+0.5094 \cdot\left(\frac{b_{i}}{a(i)}\right)^{8}\right]
\end{gathered}
$$

Note from the above that the HCF stress intensity factor amplitude increases, in a linear manner, with increasing HCF stress $\sigma_{H C F}$ and, by a more complicated function, with increasing interaction depth $b_{i}$. The calculations ${ }^{[12]}$ from Equation (A7) show that the HCF stress intensity factor amplitude increases with increasing the laser interaction depth $b_{i}$, the temperature swing $\Delta T$, as well as the thermal expansion coefficient $\alpha_{c}$ and the elastic modulus $E_{c}$ of the ceramic coating. 


\section{REFERENCES}

[1] R. A. Miller, Assessment of Fundamental Materials Needs for Thick Thermal Barrier Coatings for Truck Diesel Engines, NASA TM-103130, DOE/NASA/21794-1, May 1990.

[2] T. M. Yonushonis, Thick Thermal Barrier Coatings for Diesel Components, NASA CR187111, August 1991.

[3] T. Morel, Analysis of Heat Transfer in LHR Engines: A. Methodology, Validation, Applications; B. Translucence Effects in Ceramics, Proceedings of the 1987 Coatings for Advanced Heat Engines Workshop, Castine, Maine, July 27-30, National Information Service, U.S. Department of Commerce, Springfield, Virginia, 1987, p. II17.

[4] M. B. Beardsley and H. J. Larson, Thick Thermal Barrier Coatings for Diesel Components, DOE/NASA/0332-1, NASA CR - 190759, 1992.

[5] D. Zhu and R. A. Miller, in D. A. Shores, R. A. Rapp and P. Y. Hou (eds.), Fundamental Aspects of High Temperature Corrosion, The Electrochemical Society, Inc., Pennington, NJ 08534, 1997, p. 289.

[6] D. Zhu and R. A. Miller, On Delamination Mechanisms of Thick Thermal Barrier Coating Systems under Thermal Fatigue Conditions, in preparation.

[7] Y. R. Takeuchi and K. Kokini, Thermal Fracture of Multilayer Ceramic Thermal Barrier Coatings, Journal of Engineering for Gas Turbines and Power, 116 (1994) 266.

[8] K. Kokini, D. B. Choules and Y. Takeuchi, Thermal Fracture Mechanisms in Ceramic Thermal Barrier Coatings, Thermal Barrier Coating Workshop, Cleveland, Ohio, March 27-29, NASA Conference Publication CP-3312, Cleveland, Ohio, 1995, p. 235.

[9] C. V. Sidewell and T. A. Cruse, Mechanical Testing Program for Thermal Barrier Coating Development, Mechanical Testing Program for Thermal Barrier Coating Development, Final Report (Vanderbilt University Report 96-0801), NASA Cooperative Agreement NCC3-187, 1996.

[10] D. Zhu and R. A. Miller, Thermal Fatigue Testing of $\mathrm{ZrO}_{2}-\mathrm{Y}_{2} \mathrm{O}_{3}$ Thermal Barrier Coating Systems Using a High Power $\mathrm{CO}_{2}$ Laser, NASA Technical Memorandum TM107439, Army Research Laboratory Technical Report ARL-TR-1354, June 1997.

[11] K. Kokini, Y. R. Takeuchi and B. D. Choules, Surface Thermal Cracking of Thermal Barrier Coatings owing to Stress Relaxation: Zirconia vs. Mullite, Surface and Coatings Technology, 82 (1996) 77.

[12] D. Zhu and R. A. Miller, Influence of High Cycle Thermal Loads on Thermal Fatigue Behavior of Thick Thermal Barrier Coatings, NASA Technical Paper TP-3676, Army Research Laboratory Technical Report ARL-TR-1341, May 1997. 
[13] D. Zhu and R. A. Miller, Investigation on Thermal Fatigue Behavior of Thermal Barrier Coatings, Surface and Coatings Technology, in press.

[14] C. H. Liebert, Emittance and Absorptance of the National Aeronautics and Space Administration Ceramic Thermal Barrier Coating, Thin Solid Films, 53 (1978) 235.

[15] B. P. Johnsen, T. A. Cruse, R. A. Miller and W. J. Brindley, Compressive Fatigue of a Plasma Sprayed $\mathrm{ZrO}_{2}-8 \% \mathrm{Y}_{2} \mathrm{O}_{3}$ and $\mathrm{ZrO}_{2}-10 \% \mathrm{NiCrAlY} \mathrm{TTBC}$, Journal of Engineering Materials and Technology, 117 (1995) 305.

[16] G. Thurn, G. A. Schneider and F. Aldinger, High-temperature Deformation of Plasmasprayed $\mathrm{ZrO} 2$-Thermal Barrier Coatings, Materials Science and Engineering, in press.

[17] D. Zhu and R. A. Miller, Determination of Creep Behavior of Thermal Barrier Coatings under Laser Imposed Temperature and Stress Gradients, NASA Technical Memorandum TM-113169, November 1997.

[18] J. W. Hutchinson and Z. Suo, in J. W. Hutchinson and T. Y. Wu (eds.), Advances in Applied Mechanics, Academic Press, Inc., Boston, 1992, p. 63.

[19] D. Broek, Elementary Engineering Fracture Mechanics, Kluwer Academic Publishers, Dordrecht, 1978.

[20] Y. Murakami, Stress Intensity Factors Handbook, 108, Pergamon Press, Oxford, 1987. 

Public reporting burden for this collection of information is estimated to average 1 hour per response, including the time for reviewing instructions, searching existing data sources, gathering and mainteining the data needed, and completing and reviewing the collection of information. Send comments regarding this burden estimate or any other aspect of this Davis Highway, Suite 1204, Arlington, VA 22202-4302, and to the Office of Management and Budget, Paperwork Reduction Project (0704-0188), Washington, DC 20503.
2010

\begin{tabular}{|l|l|l} 
1. AGENCY USE ONLY (Leave blank) & $\begin{array}{c}\text { 2. REPOAT DATE } \\
\text { February } 1998\end{array}$ & $\begin{array}{r}\text { 3. REPORT TYPE AND DATES COVEAED } \\
\text { Technical Memorandum }\end{array}$
\end{tabular}

\section{TITLE AND SUBTTTLE}

Investigation of Thermal High Cycle and Low Cycle Fatigue Mechanisms of Thick Thermal Barrier Coatings

6. AUTHOR(S)

Dongming Zhu and Robert A. Miller

7. PERFORMING ORGANZATION NAME(S) AND ADDRESS(ES)

National Aeronautics and Space Administration

Lewis Research Center

Cleveland, Ohio 44135-3191

9. SPONSORINGMONITORING AGENCY NAME(S) AND ADDRESS(ES)

National Aeronautics and Space Administration

Washington, DC 20546-0001

\section{FUNDING NUMBERS}

WU-505-23-2U-00

\section{SUPPLEMENTARY NOTES}

Prepared for the Thermal Barrier Coatings Workshop sponsored by the TCB Interagency Coordinating Committee, Fort Mitchell, Kentucky, May 19-21, 1997. Dongming Zhu, National Research Council-NASA Research Associate at Lewis Research Center, and Robert A. Miller, NASA Lewis Research Center. Responsible person, Dongming Zhu, organization code 5160, (216) 433-3161.

12a. DISTAIBUTIONVAVAILABILTTY STATEMENT

Unclassified - Unlimited

Subject Categories: 24 and 27
Distribution: Nonstandard

This publication is available from the NASA Center for AeroSpace Information, (301) 621-0390.
8. Performing organization REPORT NUMBER

E-11091

10. SPONSORINGMONITORING AGENCY REPOAT NUMBER

NASA TM-1998-206633

13. ABSTAACT (Maximum 200 words)

Thick thermal barrier coating systems in a diesel engine experience severe thermal low cycle fatigue (LCF) and high cycle fatigue (HCF) during engine operation. In this paper, the mechanisms of fatigue crack initiation and propagation in a $\mathrm{ZrO}_{2}-8 \mathrm{wt} . \% \mathrm{Y}_{2} \mathrm{O}_{3}$ thermal barrier coating, under simulated engine thermal LCF and HCF conditions, are investigated using a high power $\mathrm{CO}_{2}$ laser. Experiments showed that the combined LCF/HCF tests induced more severe coating surface cracking, microspallation and accelerated crack growth, as compared to the pure LCF test. Lateral crack branching and the ceramic/bond coat interface delaminations were also facilitated by HCF thermal loads, even in the absence of severe interfacial oxidation. Fatigue damages at crack wake surfaces, due to such phenomena as asperity/debris contact induced cracking and splat pull-out bending during cycling, were observed especially for the combined LCF/HCF tests. It is found that the failure associated with LCF is closely related to coating sintering and creep at high temperatures, which induce tensile stresses in the coating after cooling. The failure associated with HCF process, however, is mainly associated with a surface wedging mechanism. The interaction between the LCF, HCF and ceramic coating creep, and the relative importance of LCF and HCF in crack propagation are also discussed based on the experimental evidence. 14. SUBJECT TERMS
Thermal barrier coatings; Thermal high cycle and low cycle fatigue; Ceramic sintering and
creep; Fatigue mechanisms

17. SECURTY CLASSIFICATION OF REPORT

Unclassified
18. SECURITY CLASSIFICATION

Unclassified OF THIS PAGE
19. SECURITY CLASSIFICATION

Unclassified OF ABSTRACT

NSN 7540-01-280-5500

15. NUMBER OF PAGES 32

16. PRICE CODE $\mathrm{A} 03$

Standard Form 298 (Rev. 2-89)

Prescribed by ANSI Std. Z39-18 298-102 